\title{
An analysis of how long-term university-industry linkages affects academic research productivity
}

\author{
Renato Garcia (presenting author) \\ Institute of Economics at University of Campinas, Brazil; renatogarcia@eco.unicamp.br. \\ Veneziano Araújo \\ Emerson Gomes dos Santos \\ Federal University of São Paulo, Brazil \\ Suelene Mascarini \\ Federal University of São Carlos, Sorocaba, Brazil \\ Ariana Ribeiro Costa \\ Polytechnic School of University of São Paulo, Brazil \\ (Paper presented at the Brazilian National Meeting of Economics of \\ Innovation - II ENEI 2017, Rio de Janeiro, $1^{\text {st }}-3^{\text {rd }}$ August 2017)
}

\begin{abstract}
The aim of this paper is to analyse the impact of long-term university-industry collaboration on academic research productivity. Empirical evidence shows that in general, collaboration with industry positively affects scientific productivity. However, there is a lack of understanding of the long-term effect of collaboration. This paper addresses that concern through the use of a unique longitudinal and comprehensive dataset on university-industry collaboration in Brazil. The results show that over the long term, research groups that collaborate with industry present better scientific performance, allowing for the conclusion that long-term collaboration between research groups and firms has a positive effect on academic productivity.
\end{abstract}

Key words: university-industry collaboration; scientific productivity; long-term collaboration

JEL Code: O31; O38; 23 


\section{An analysis of how long-term university-industry linkages affects academic research productivity}

\section{Introduction}

The increasing importance of university-industry collaboration has raised concerns about the potential effects that collaboration with firms has on academic productivity. Many studies have found that university-industry collaboration has a positive effect on scientific productivity. However, other studies have found either that the positive effects are limited or that collaboration with industry can have negative effects on scientific productivity.

This paper aims to analyse the impact of long-term university-industry collaboration on academic research productivity. We describe four main gaps in the literature that this paper aims to fill with new contributions. First, we examine the effect of collaboration with industry on scientific productivity using data on university-industry linkages such as collaborative projects. Previous studies of the effects on scientific productivity primarily use formal channels of interactions such as patents, licences and spin-offs. Data on collaboration with industry presents several advantages over data on collaborative project-based links with industry such as patents, licences and spin-offs. For firms and universities, collaboration projects with industry are both more widespread and more important for technology transfer (D'Este \& Patel 2007; Cohen et al. 2002; Agrawal \& Henderson 2002; Banal-Estañol et al. 2015).

Second, we present new findings on both the long-term effect of collaboration with industry on scientific productivity and the empirical evidence on how collaboration with industry affects scientific production over time. Third, our results show that the benefits of collaboration with industry decrease over time, revealing that those benefits are not unlimited. No previous studies have found this non-linear relation between collaboration with industry and scientific production over time. Fourth, previous studies on the effects of collaboration with industry on scientific production primarily focused on developed countries, whereas this paper focuses on Brazil, a developing country.

The data used in this paper comprise a unique longitudinal and comprehensive database of university-industry collaboration in Brazil from the Census of Research Groups Directory in the Lattes database of the Ministry of Science and Technology. Data from 2002 to 2008 not only distinguish collaborative and non-collaborative research groups but also provide information about those groups' characteristics and scientific 
performance. As in developed countries, academic research plays an increasing role in fostering innovation in developing countries (De Fuentes \& Dutrénit 2012; Ranga et al. 2016) such as Brazil (Albuquerque 2007; Suzigan et al. 2009; Fernandes et al. 2010; Moraes-Silva et al. 2017). Brazilian universities are playing a more prominent role in fostering innovation in several industries, with a notable impact on the share of several domestic firms in international markets (Suzigan \& Albuquerque 2011). However, the experiences of developing countries' less-developed institutional and economic environments suggest that university-industry collaborations could have different natures and determinants in developing countries than in developed countries (Albuquerque 2007; Moraes-Silva et al. 2017). For example, unlike in developed countries, in developing countries the most important areas in which technology transfer occurs are engineering and agrarian sciences (Suzigan et al. 2009). University research is particularly important to medium- and lower-technology industries because Brazilian firms' research and development (R\&D) expenditures are relatively low, particularly in high-technology industries (Albuquerque 2007; Suzigan et al. 2009). The regional distribution of university-industry linkages is strongly unequal and concentrated in the southern part of the country (Garcia et al. 2015).

Our empirical strategy for estimating the effect of long-term university-industry collaborations in the scientific production of research groups involves a difference-indifferences (DID) approach with a matching technique based on Propensity Score Matching (PSM). The use of PSM in conjunction with DID reduces potential selection biases in the sampling.

This paper is organized into four sections. Section two presents the conceptual background of the effects of collaboration on scientific productivity. Section three provides a brief description of the dataset and the main methodological issues. Section four presents the results and discusses the main evidence for the long-term effects of collaboration with industry on scientific productivity. Section five presents concluding remarks and policy implications.

\section{University-industry collaboration and scientific productivity: positive and negative effects}

The increasing importance of university-industry collaboration over the last two decades has raised several concerns about the potential effects of collaboration with firms on academic productivity. The university's role in fostering innovation has been 
recognized, and university-industry collaboration is an important means for academic researchers and industrial scientists to share knowledge (Cohen et al. 2002; Mowery \& Sampat 2009).

From the university's perspective, collaboration raises important concerns. The economic benefits of collaboration could shift academic researchers' orientation, driving them away from basic research and harming academic productivity (Merton 1976; Dasgupta \& David 1994; Breschi et al. 2008; Tartari \& Breschi 2012). Collaboration can have several potentially damaging effects on academic researchers' behaviour by weakening their commitment to the principles of open science and stimulating adverse behaviours such as withholding data, engaging in secrecy and delaying publication. (Dasgupta \& David 1994; Merton 1976). Academic researchers' work is based on the principles of research autonomy and the wide dissemination of newly generated knowledge, and their incentive systems are based on reputation and peer recognition (Nelson 2004; Tartari \& Breschi 2012; Merton 1976; Dasgupta \& David 1994). Industrial scientists seek the benefits of the use of private knowledge to generate new or improved products and processes. Industrial research aims for short-term results derived from the commercialization of new knowledge, which requires proprietary technologies and the limited exchange of information and knowledge (Tartari et al. 2012; Rosenberg 1990; Dasgupta \& David 1994; Perkmann \& Walsh 2009).

Collaboration with industry can benefit academic research in several ways. The main benefits might be economic, such as financial resources for the research group access to costly laboratories, and other academic resources or benefits such as the exchange of information and knowledge sharing between academic researchers and industrial scientists. (Arza 2010; Perkmann \& Walsh 2009). Collaboration with industry can provide closer contacts between industrial scientists and academic researchers and can be a very important source of new ideas. Thus, collaboration can have positive effects on generating new ideas for research projects and upgrading the academic research agenda (Breschi et al. 2008; Tartari \& Breschi 2012).

With respect to collaborations between industrial scientists and academic researchers, various studies have made claims about how collaboration affects scientific productivity (Landry et al. 1996; Blumenthal et al. 1996; Bozeman et al. 2013; Lee 2000; Agrawal \& Henderson 2002). However, empirical studies have found mixed evidence. Many studies have found a positive relationship between university-industry collaboration and scientific productivity (Ranga et al. 2003; Van Looy et al. 2011; Rivera- 
Huerta et al. 2011; Banal-Estañol et al. 2013; Van Looy et al. 2004; Abramo et al. 2009; Lee \& Bozeman 2005; Landry et al. 1996; Tartari \& Breschi 2012; Steinmo 2015). Some studies have noted that positive effects only occur under specific conditions (Bonaccorsi et al. 2006; Manjarrés-Henríquez et al. 2009; Banal-Estañol et al. 2013), whereas others have found that collaboration can have negative effects on scientific productivity (Bonaccorsi \& Piccaluga 1994; Hottenrott \& Thorwarth 2011; Blumenthal et al. 1996; Manjarrés-Henríquez et al. 2009; Banal-Estañol et al. 2015).

In general, the positive effects of collaboration with industry are related to academic benefits that emerge from the collaboration because links with industry can expand and upgrade the academic research agenda. Economic benefits, especially access to financial and non-financial resources, have also been mentioned (Tartari \& Breschi 2012; Banal-Estañol et al. 2015). However, these positive effects are often only apparent if the university research group develops $R \& D$ contracts with its industrial partner (Manjarrés-Henríquez et al. 2009). The amount of funds obtained for the collaboration also affects the positive effects. Previous studies have found that when the total resources from collaboration are greater than $15 \%$ of a research group's total budget, the collaboration negatively affects scientific productivity (Manjarrés-Henríquez et al. 2008). A curvilinear inverted U-shape curve between the degree of collaboration and scientific productivity has also been found (Banal-Estañol et al. 2015). Collaborative projects with industry can enhance academic research projects and consequently, research output because such projects can provide new ideas and funding for academic research. However, a high degree of collaboration can damage research publication because new ideas might be of lower value, industry can impose disclosure conditions, or collaborative projects could reduce the potential for academic research, creating time-management problems (Banal-Estañol et al. 2015). This line of argument leads to the following testable hypothesis:

H1: University-industry collaborations increase the scientific productivity of academic research groups.

It is important to note the long-term effects of collaboration with industry on scientific productivity. The benefits of collaboration with industry can occur with greater intensity over the long term, when different and powerful interaction mechanisms act to reduce orientation barriers related to differences in universities and businesses' 
orientation and transaction barriers related to intellectual property conflicts and contract management (Bruneel et al. 2010; Tartari et al. 2012; Perkmann \& Walsh 2009; Arza 2010; Dutrénit et al. 2010; Rivera-Huerta et al. 2011; Lee 2000; Lee \& Bozeman 2005). Partners' increasing experience in collaboration, the breadth of interactive projects, and the creation of mutual trust between the partners are the primary factors that lower barriers to collaboration over time (Cantner et al. 2017; Rivera-Huerta et al. 2011). Another hypothesis can be stated:

H2: Long-term collaborations with industry increase the scientific productivity of academic research groups.

The second hypothesis is the most important because there is a lack of understanding of how long-term university-industry collaboration affects scientific productivity. We provide new empirical evidence on this issue.

\section{Database}

\subsection{Methodological Approach}

In our research design, we apply a DID approach to assess the impact of academic collaboration with industry on the university research groups' scientific production and compare them with the production of other academic research groups that do not collaborate with industry. This method is widely used in econometric studies (Card \& Krueger 1994; Heckman et al. 1998) and is based on a quasi-experimental research design that compares the mean value of a dependent variable over time between treatment and control groups. After an initial period, the treatment group is subject to an intervention that does not occur in the control group.

The DID method generally eliminates problems of selection bias associated with single-population time series or static comparisons because the inference is made using the same observation across time. When panel data are available, they are useful for inferring the effect of a certain treatment. However, DID assumes that the treatment and control groups are similar before the treatment. The composition of the sample could generate potential biases in the DID method. The most common problem is related to the fact that the treatment group is not random and could present self-selection issues, generating a group that is different from the general population. Applying this issue to 
university-industry collaboration, research groups with characteristics such as staff qualification, team size, age, scientific field, affiliation and location are more likely to collaborate with industry.

To manage this potential selection bias and for a more accurate DID analysis, covariate matching techniques focused on reducing the difference between the covariate distributions for treatment and control groups can be used. Matching techniques add a more fine-grained comparison between the two samples, ensuring similarity and thus improving comparability (Rubin 1980). The matching technique is PSM (Rubin 1976), which focuses on reducing bias across simultaneous covariates and is a widely used and accepted method for drawing causal estimates of effect size (Dehejia \& Wahba 2002). It is built by matching research groups of treated and non-treated samples that present similar propensity scores. To estimate the propensity score, a logit or probit model is usually employed to determine the likelihood of the treatment group based on observable pre-treatment covariates. The PSM procedure reduces both the imbalance between the treatment and the control groups and the selection bias, resulting in a more precise estimation.

Combining DID and PSM is a powerful method to estimate treatment effects (Heckman et al. 1998). DID controls for unobserved heterogeneity between treated and non-treated research groups. The PSM matching technique controls selection bias, avoiding treated and non-treated groups of different compositions. In this paper, we use two DID methods, standard DID and DID with PSM, allowing us both to interpret results across different estimations and to generate more robust results.

\subsection{Assembly of the dataset}

Data on university-industry collaborations in Brazil were gathered from the Census of Research Groups Directory of the Ministry of Science and Technology's Lattes database. The Census collects two-year basis information; we used data from the 2002, 2004, 2006 and 2008 editions. The database provides comprehensive information from 8,053 academic research groups in Brazil, providing information for all editions of the Census. The information comprises the main characteristics of academic research groups such as institutional affiliation, scientific field, number of researchers, scientific publications, location and collaboration with industry.

The target population covers all research groups that provide information for all editions of the Census. The database is longitudinal and comprehensive, with research 
groups in all scientific fields and all regions of the country; it includes IPR, public and private institutions. We removed research groups that collaborated in the initial period (2002) because the DID method assumes that the treatment and control groups were not previously exposed to the treatment. This procedure ensures that we are comparing the effect of collaboration with industry on the scientific production of research groups that started a new collaboration during the treatment period against research groups that did not collaborate during the same period.

The final dataset is composed of 7,572 academic research groups. It includes information on research groups' basic characteristics, such as size, the researchers' qualifications, age, scientific field, region, institutional affiliation, and scientific production. On average, each research group had $4 \mathrm{Ph}$.D. researchers and published 38.6 articles in the two years before the 2002 census. Among the 7,572 research groups, 857 (11.3\%) collaborated with industry during the studied period. Of those research groups, 324 (4.3\% of the sample) collaborated over the entire period, except for the initial year. In our context, collaborations represent the treatment given to individuals (i.e., academic research groups), whereas the control research groups are non-treated individuals. To evaluate the effect of such a treatment, we used DID.

Table 1 presents the main variable of the final dataset, Table 2 presents the descriptive statistics and Table 3 presents the sample of collaborating research groups and the population of non-collaborating research groups.

Table 1 about here

Table 2 about here

Table 3 about here

We conducted PSM using Kernel-based matching in a logit model. The means of each pre-treatment covariate for the treatment (i.e., the matched and unmatched control groups) are summarized in Table 4. It is possible to ensure that there is no statistically significant difference between the treatment and control groups after PSM.

Table 4 about here

\section{Results and discussion}


We estimated an econometric model to empirically test the two hypotheses:

H1: University-industry collaborations increase the scientific productivity of academic research groups.

H2: Long-term collaborations with industry increase the scientific productivity of academic research groups.

Two different econometric approaches were used to estimate the effects of collaboration with industry. First, we estimated using standard unmatched DID. Second, we estimated using DID with PSM, which allows us to estimate the regression for the entire sample of treated and control research groups. The results of the estimations are presented in Table 5.

Table 5 about here.

In both cases, the estimated effect is both positive and significant. The second estimation is more accurate because it includes the PSM and allows us to note the effect of each collaboration in the number of papers published by each academic research group. The findings show that although the DID-PSM estimated effects are lower than the effects of the standard DID, they have higher statistical significance (Table 6).

Table 6 about here.

The results are presented by sorting out long-term collaborations. Long-term collaboration is defined as research groups that collaborate with industry over the entire period analysed. Thus, the first estimation of the analysis shows the effect of the collaboration on the scientific productivity of all research groups that collaborate with industry, even though that collaboration may have occurred during only a single year of the analysed period. The second estimation shows only long-term collaborations.

Considering all collaborations, the findings show that collaboration with industry generally has a positive effect on scientific productivity. The effect of collaboration represents an increase in scientific production of 5.832 papers per research group over the entire period. When comparing this result to the control group, the effect of collaboration implies an increase of $12.8 \%$ in the scientific production of the collaborating research groups. This finding supports hypothesis $\mathrm{H} 1$ and corroborates the results of previous studies finding that both technology transfer from universities to industry and 
collaboration with firms have positive effects on scientific productivity (Landry et al. 1996; Van Looy et al. 2004; Abramo et al. 2009; Banal-Estañol et al. 2015).

The positive effects of long-term collaboration are even greater. Scientific production increases by 7.266 published papers, $15.4 \%$ more than the control group. This finding supports hypothesis $\mathrm{H} 2$ and represents new empirical evidence on the effects of long-term collaboration with industry. Previous studies noted that the experience of collaboration with industry lowers orientation and transaction barriers to collaboration over time because it promotes a better understanding between academic researchers and industrial scientists and increases mutual trust (Bruneel et al. 2010; Rivera-Huerta et al. 2011; Tartari et al. 2012; Perkmann \& Walsh 2009; Arza 2010; Dutrénit et al. 2010; Lee 2000; Lee \& Bozeman 2005). However, there is a lack of empirical evidence of these long-term effects. This finding represents a new contribution regarding empirical evidence of the effects of long-term collaboration with industry on scientific production. This shows that collaborative research projects positively affect the scientific production of collaborative research groups in comparison with non-collaborative research groups.

The positive effects of collaboration with industry on scientific productivity can also be analysed by examining how these effects evolve over time. To do so, separate DID specifications were estimated for the 2002-04, 2002-06 and 2002-08 periods using only research groups that engaged in long-term collaboration. This specification enables us to examine the degree of the effects of collaboration with industry on a research group's scientific production for each period analysed. This allows us to analyse the trend in the research group's scientific production (Table 7).

Table 7 about here.

In the first analysed period (2002-04), the effects are quite small-1.536 published papers per collaborating research group - and have no statistical significance. This finding indicates that the main benefits of collaboration with industry occur over time and could be quite small in the short term. In the second period (2002-06), the positive effects of collaboration are statistically significant and show an increase of 5.038 papers per collaborative research group. For the entire period (2002-08), positive effects can be seen, but the increase occurs at a lower rate, representing an increase of 7.141 papers per research group. This finding indicates that there may not be an unlimited increase in research groups' scientific production because they cannot afford larger increases in 
publication. This result means that long-term collaboration with industry has strong positive effects on a research group's scientific production. However, these effects have limits, which are related to the characteristics of each research group.

As a robustness check ${ }^{1}$ to ensure that our DID results are not sensitive to alternative PSM specifications, we performed estimations using five different PSM approaches, varying the kernel type, bandwidth and estimation technique. The results are presented in Table 6 and as expected, the main results are the same.

All of the research groups that began to collaborate had more publications in 2008. Moreover, the effects on academic publication are stronger for long-term collaborations than for short-term ones. To illustrate this disparity, we subtracted the short-term effects from the long-term effects in the bottom row of Table 6. This shows that long-term collaboration's effect on academic production ranges from 1.25 to 2.06 additional publications.

\section{Final remarks and policy implications}

There is controversy regarding the effects of university-industry collaboration on scientific productivity. Some studies emphasize the benefits of collaboration, focusing on the opportunity to benefit from industrial scientists' complementary capabilities (Landry et al. 1996; Geuna \& Nesta 2006; Breschi et al. 2007; Abramo et al. 2009; Banal-Estañol et al. 2015; Dutrénit et al. 2010). Other studies note the limits of the benefits of collaboration with industry (Bonaccorsi et al. 2006; Manjarrés-Henríquez et al. 2008; Banal-Estañol et al. 2015).

This paper aims to present new empirical evidence of the long-term effect of collaboration with industry on scientific production by examining this issue in relation to collaborative projects involving academic research and industrial R\&D groups in Brazil. The empirical strategy involves DID and PSM to compare collaborative and noncollaborative research groups. Three main results are noted. First, in agreement with previous studies, collaboration with industry has positive effects on scientific productivity because research groups that collaborate with industry publish more papers than research

\footnotetext{
${ }^{1}$ To ensure that our control group is correct and consistent, we removed all research groups that had collaborations. Next, we performed 100 random DIDs (assigned random control as treated). This test ensured that the null hypothesis that the mean effect is equal to zero cannot be rejected, reaffirming the validity of the control group.
} 
groups that do not. Second, over the long term, the effects of collaboration tend to be higher because the difference in scientific production between collaborative and noncollaborative research groups tends to be higher over time. Third, there are limits to the positive effects of collaboration over time because the empirical evidence shows that the increase in benefits attributable to a long-term collaboration occurs at a decreasing rate.

Finally, these findings have policy implications. Several studies noted that policies of stimulating stimulate university-industry linkages play a role in fostering innovation (Dasgupta \& David 1994; Cohen et al. 2002; Albuquerque 2007). This paper's findings reinforce the role of policy from the standpoint of academic research because university research groups benefit from collaboration with industry, especially from long-term collaborative projects. Policies should include requirements for academic researchers to publish new papers related to their collaboration projects because academic researchers must be able to create mechanisms to benefit from the complementary capabilities of industrial scientists with whom they collaborate. This will allow academic researchers and industrial scientists to strengthen the generation and dissemination of new scientific and technological knowledge. Moreover, because the long-term benefits of collaboration are higher than the short-term benefits, policy should establish mechanisms that encourage the maintenance of relationships over time, especially through programmes that consider the duration of collaboration between academic researchers and industrial scientists.

\section{References}

Abramo, G. et al., 2009. University-industry collaboration in Italy: A bibliometric examination. Technovation, 29(6-7), pp.498-507.

Agrawal, A. \& Henderson, R., 2002. Putting patents in context: Exploring knowledge transfer from MIT. Management science, 48(1), pp.44-60.

Albuquerque, E. da M., 2007. Inadequacy of technology and innovation systems at the periphery. Cambridge Journal of Economics, 31(5), pp.669-690.

Arza, V., 2010. Channels, benefits and risks of public-private interactions for knowledge transfer: conceptual framework inspired by Latin America. Science and Public Policy, 37(7), pp.473-484. Available at: http://www.ingentaconnect.com/content/beech/spp.

Banal-Estañol, A., Jofre-Bonet, M. \& Lawson, C., 2015. The double-edged sword of industry collaboration: Evidence from engineering academics in the UK. Research Policy, 44(6), pp.1160 1175 .

Banal-Estañol, A., Macho-Stadler, I. \& Pérez-Castrillo, D., 2013. Research output from university-industry collaborative projects. Economic Development Quarterly, 27(1), pp.71-81.

Blumenthal, D. et al., 1996. Relationships between academic institutions and industry in the life sciences- 
-an industry survey. The New England journal of medicine, 334(6), pp.368-373.

Bonaccorsi, A., Daraio, C. \& Simar, L., 2006. Advanced indicators of productivity of universitiesAn application of robust nonparametric methods to Italian data. Scientometrics, 66(2), pp.389-410.

Bonaccorsi, A. \& Piccaluga, A., 1994. A theoretical framework for the evaluation of university-industry relationships. $R \& D$ Management, 24(3), pp.229-247.

Bozeman, B., Fay, D. \& Slade, C.P., 2013. Research collaboration in universities and academic entrepreneurship: the-state-of-the-art. The Journal of Technology Transfer, 38(1), pp.1-67.

Breschi, S., Lissoni, F. \& Montobbio, F., 2007. The Scientific Productivity of Academic Inventors: New Evidence From Italian Data. Economics of Innovation and New Technology, 16(2), pp.101-118.

Breschi, S., Lissoni, F. \& Montobbio, F., 2008. University patenting and scientific productivity: a quantitative study of Italian academic inventors. European Management Review, 5(2), pp.91-109.

Bruneel, J., D'Este, P. \& Salter, A., 2010. Investigating the factors that diminish the barriers to universityindustry collaboration. Research Policy, 39(7), pp.858-868.

Cantner, U., Hinzmann, S. \& Wolf, T., 2017. The Coevolution of Innovative Ties, Proximity, and Competencies: Toward a Dynamic Approach to Innovation Cooperation. In Knowledge and Networks. Springer, pp. 337-372.

Card, D. \& Krueger, A., 1994. Minimum wages and employment: A case study of the fast food industry in New Jersey and Pennsylvania. American Economic Review, 84(4), pp.772-793. Available at: http://www.jstor.org/stable/2118030.

Cohen, W.M., Nelson, R.R. \& Walsh, J.P., 2002. Links and Impacts: The Influence of Public Research on Industrial R\&D. Management Science, 48(June 2015), pp.1-23.

D'Este, P. \& Patel, P., 2007. University-industry linkages in the UK: What are the factors underlying the variety of interactions with industry? Research Policy, 36(9), pp.1295-1313.

Dasgupta, P. \& David, P.A., 1994. Toward a new economics of science. Research Policy, 23(5), pp.487521.

Dehejia, R.H. \& Wahba, S., 2002. Propensity Score-Matching Methods for Nonexperimental Causal Studies. Review of Economics and Statistics, 84(1), pp.151-161.

Dutrénit, G., De Fuentes, C. \& Torres, A., 2010. Channels of interaction academy-industry and benefits from firms and researchers ${ }^{e e}$ perspective: evidence from Mexico. Science and Public Policy, 37(7), pp.513-526.

Fernandes, A.C. et al., 2010. Academy -industry links in Brazil: evidence about channels and benefits for firms and researchers. Science and Public Policy, 37(7), pp.485-498.

De Fuentes, C. \& Dutrénit, G., 2012. Best channels of academia-industry interaction for long-term benefit. Research Policy, 41(9), pp.1666-1682.

Garcia, R. et al., 2015. Looking at both sides: how specific characteristics of academic research groups and firms affect the geographical distance of university--industry linkages. Regional Studies, Regional Science, 2(1), pp.518-534.

Geuna, A. \& Nesta, L.J.J., 2006. University patenting and its effects on academic research: The emerging European evidence. Research Policy, 35(6), pp.790-807.

Heckman, J.J., Ichimura, H. \& Todd, P., 1998. Matching As An Economic Evaluation Estimator. Review of Economic Studies, 65(2), pp.261-294. Available at: http://restud.oxfordjournals.org/content/65/2/261.short.

Hottenrott, H. \& Thorwarth, S., 2011. Industry funding of university research and scientific productivity. Kyklos, 64(4), pp.534-555.

Landry, R., Traore, N. \& Godin, B., 1996. An econometric analysis of the effect of collaboration on academic research productivity. Higher Education, 32(3), pp.283-301. 
Lee, S. \& Bozeman, B., 2005. The impact of research collaboration on scientific productivity. Social studies of science, 35(5), pp.673-702.

Lee, Y.S., 2000. The sustainability of university-industry research collaboration: An empirical assessment. The Journal of Technology Transfer, 25(2), pp.111-133.

Van Looy, B. et al., 2004. Combining entrepreneurial and scientific performance in academia: Towards a compounded and reciprocal Matthew-effect? Research Policy, 33(3), pp.425-441.

Van Looy, B. et al., 2011. Entrepreneurial effectiveness of European universities: An empirical assessment of antecedents and trade-offs. Research Policy, 40(4), pp.553-564.

Manjarrés-Henríquez, L. et al., 2009. The effects of university-industry relationships and academic research on scientific performance: Synergy or substitution? Research in Higher Education, 50(8), pp.795-811.

Manjarrés-Henríquez, L., Gutiérrez-Gracia, A. \& Vega-Jurado, J., 2008. Coexistence of universityindustry relations and academic research: Barrier to or incentive for scientific productivity. Scientometrics, 76(3), pp.561-576.

Merton, R.K., 1976. The Sociology of Science: Theoretical and Empirical Investigations. Contemporary Sociology, 5, p.555.

Moraes-Silva, D.R., Furtado, A.T. \& Vonortas, N.S., 2017. University-industry R\&amp;D cooperation in Brazil: a sectoral approach. The Journal of Technology Transfer. Available at: http://link.springer.com/10.1007/s10961-017-9566-z.

Mowery, D.C. \& Sampat, B.N., 2009. Universities in National Innovation Systems. In The Oxford Handbook of Innovation. pp. 209-239.

Nelson, R.R., 2004. The market economy, and the scientific commons. Research Policy, 33(3), pp.455471.

Perkmann, M. \& Walsh, K., 2009. The two faces of collaboration: Impacts of university-industry relations on public research. Industrial and Corporate Change, 18(6), pp.1033-1065.

Ranga, L., Debackere, K. \& Tunzelmann, N., 2003. Entrepreneurial universities and the dynamics of academic knowledge production: A case study of basic vs. applied research in Belgium. Scientometrics, 58(2), pp.301-320.

Ranga, M. et al., 2016. Building Technology Transfer Capacity in Turkish Universities: A critical analysis. European Journal of Education, 51(1), pp.90-106.

Rivera-Huerta, R. et al., 2011. Do linkages between farmers and academic researchers influence researcher productivity? the Mexican case. Research Policy, 40(7), pp.932-942.

Rosenberg, N., 1990. Why do firms do basic research (with their own money)? Research Policy, 19(2), pp.165-174.

Rubin, D.B., 1980. Bias Reduction Using Mahalanobis-Metric Matching. Biometrics, 36(2), pp.293-298. Available at: http://www.jstor.org/stable/2529981.

Rubin, D.B., 1976. Multivariate Matching Methods That are Equal Percent Bias Reducing. Biometrics, 32(1), pp.109-120. Available at: http://www.ncbi.nlm.nih.gov/entrez/query.fcgi?db=pubmed\&cmd=Retrieve\&dopt=AbstractPlus\&li st_uids=2529342\%5Cnpapers://e7842f84-48e9-486c-a619-14a211cc4e62/Paper/p1593.

Steinmo, M., 2015. Collaboration for Innovation: A Case Study on How Social Capital Mitigates Collaborative Challenges in University-Industry Research Alliances. Industry and Innovation, 22(7), pp.597-624. Available at: http://www.tandfonline.com/doi/full/10.1080/13662716.2015.1105127\%5Cnhttp://dx.doi.org/10.10 80/13662716.2015.1105127.

Suzigan, W. et al., 2009. University and Industry Linkages in Brazil: Some Preliminary and Descriptive Results. Seoul Journal of Economics, 22(4), pp.591-611. Available at: http://search.ebscohost.com/login.aspx?direct=true \&db=ecn\&AN=1098093\&site=bsi- 
live\%5Cnhttp://www.sje.ac.kr.

Suzigan, W. \& Albuquerque, E.D.M.E., 2011. The underestimated role of universities for the Brazilian system of innovation. Revista de Economia Política, 31(1), pp.03-30. Available at: http://www.scielo.br/scielo.php?pid=S0101-31572011000100001\&script=sci_arttext.

Tartari, V. \& Breschi, S., 2012. Set them free: Scientists' evaluations of the benefits and costs of university-industry research collaboration. Industrial and Corporate Change, 21(5), pp.1117-1147.

Tartari, V., Salter, A. \& D’Este, P., 2012. Crossing the rubicon: Exploring the factors that shape academics' perceptions of the barriers to working with industry. Cambridge Journal of Economics, 36(3), pp.655-677. 


\section{Tables and Figures}

Table 1. Description of the variables

\begin{tabular}{ll}
\hline Variable & Definition \\
\hline Papers & Scientific papers in journals published in the last two years. \\
Collab & Group collaborate with firms in the current census edition \\
All Collab & Group collaborate with firms in at least one census from 2004-2008 \\
Long-term Collab & Group collaborate with firms in all censuses (2004, 2006 and 2008) \\
Team Size & Number of PhD researchers affiliated to the group in the current year \\
PhD Res & Share of PhD researchers and total researchers (non-PhD) in the current year \\
Team Age & Number of years since the research group started activities \\
Scientific Areas & Dummies for Scientific Areas. \\
Location & Dummies for Brazilian macro regions. \\
Affiliation & Dummies for: Public University, Private University and Public Research Institution. \\
Source: authors' original work based on Brazilian Ministry of Science and Technology.
\end{tabular}


Table 2. Descriptive Statistics

\begin{tabular}{clrrrr}
\hline Variables & & Mean & Std dev & Min & Max \\
\hline Articles & & 27,727 & 5,539 & 0 & 1459 \\
All Collab & & 0,113 & 0,317 & 0 & 1 \\
Long-term & & 0,043 & 0,202 & 0 & 1 \\
Collab & & 0,059 & 0,235 & 0 & 1 \\
Collab & & 5,291 & 4,300 & 0 & 98 \\
Team Size & & 0,793 & 0,268 & 0 & 1 \\
PhD_Res & & 9,314 & 7,482 & 0 & 76 \\
Team Age & & 0,103 & 0,304 & 0 & 1 \\
& Agricultural Sci & 0,162 & 0,368 & 0 & 1 \\
& Biological Sci & 0,103 & 0,304 & 0 & 1 \\
& Engineering & 0,174 & 0,379 & 0 & 1 \\
ScieField & Natural Sci & 0,164 & 0,370 & 0 & 1 \\
& Humanities & 0,050 & 0,217 & 0 & 1 \\
& Languages & 0,167 & 0,373 & 0 & 1 \\
& Health Sci & 0,079 & 0,269 & 0 & 1 \\
\hline \multirow{5}{*}{ Location } & Social Sci & 0,050 & 0,217 & 0 & 1 \\
& Center-West & 0,031 & 0,172 & 0 & 1 \\
& North & 0,136 & 0,343 & 0 & 1 \\
& Northeast & 0,245 & 0,430 & 0 & 1 \\
& South & 0,538 & 0,499 & 0 & 1 \\
\hline & Southeast & 0,091 & 0,287 & 0 & 1 \\
& PRI & 0,261 & 0,439 & 0 & 1 \\
& Private Univ & 0,648 & 0,478 & 0 & 1 \\
\hline Source: authors' & Public Univ & & & &
\end{tabular}

Source: authors' original work.

Table 3. Number of collaborative and non-collaborative academic research groups in the data set

\begin{tabular}{|c|c|c|c|c|c|c|}
\hline Research Group & 2002 & 2004 & 2006 & 2008 & $\begin{array}{c}\text { Long-term } \\
\text { colaboration }\end{array}$ & $\begin{array}{c}\text { One period } \\
\text { collaboration }\end{array}$ \\
\hline Collaboration & 0 & 411 & 622 & 745 & 324 & 857 \\
\hline No collaboration & 7,572 & 7,161 & 6,950 & 6,827 & 7,248 & 6,715 \\
\hline
\end{tabular}

Source: authors' original work. 
Table 4. Means of each pre-treatment covariate for all treatment, matched and unmatched control groups

\begin{tabular}{|c|c|c|c|c|c|c|c|c|}
\hline Variable & & $\begin{array}{c}\text { Treated } \\
\text { (A) }\end{array}$ & $\begin{array}{c}\text { Untreated } \\
\text { (B) }\end{array}$ & Diff (A-B) & p-value & $\begin{array}{c}\text { Control } \\
\text { (C) }\end{array}$ & Diff (A-C) & p-value \\
\hline Articles & & 18.848 & 16.669 & 2.179 & $0.0582^{*}$ & 18.545 & 0.304 & 0.6998 \\
\hline Team Size & & 4.495 & 3.942 & 0.553 & $0.0000^{* * * *}$ & 4.348 & 0.147 & $0.0757^{*}$ \\
\hline PhD_Res & & 0.745 & 0.751 & -0.006 & 0.5661 & 0.746 & -0.001 & 0.8957 \\
\hline Team Age & & 6.736 & 6.346 & 0.390 & 0.1353 & 6.702 & 0.034 & 0.8432 \\
\hline \multirow{8}{*}{ ScieField } & Agricultural Sci & 0.186 & 0.092 & 0.093 & $0.0000^{* * * *}$ & 0.176 & 0.010 & 0.2662 \\
\hline & Biological Sci & 0.127 & 0.166 & -0.039 & $0.0035^{* * * *}$ & 0.135 & -0.007 & 0.3431 \\
\hline & Engineering & 0.238 & 0.085 & 0.153 & $0.0000^{* * * *}$ & 0.224 & 0.014 & 0.1586 \\
\hline & Natural Sci & 0.191 & 0.172 & 0.020 & 0.1528 & 0.181 & 0.010 & 0.2639 \\
\hline & Humanities & 0.078 & 0.175 & -0.097 & $0.0000^{* * *}$ & 0.089 & -0.011 & $0.0985^{*}$ \\
\hline & Languages & 0.007 & 0.055 & -0.048 & $0.0000^{* * * *}$ & 0.009 & -0.002 & 0.2597 \\
\hline & Health Sci & 0.113 & 0.173 & -0.060 & $0.0000^{* * * *}$ & 0.123 & -0.010 & 0.1831 \\
\hline & Social Sci & 0.060 & 0.081 & -0.022 & $0.0267^{* *}$ & 0.063 & -0.003 & 0.5333 \\
\hline \multirow{5}{*}{ Location } & Center-West & 0.067 & 0.048 & 0.019 & $0.0168^{* *}$ & 0.061 & 0.006 & 0.2858 \\
\hline & North & 0.046 & 0.029 & 0.017 & $0.0067^{* * *}$ & 0.041 & 0.004 & 0.3831 \\
\hline & Northeast & 0.139 & 0.136 & 0.003 & 0.8256 & 0.143 & -0.004 & 0.6370 \\
\hline & South & 0.291 & 0.240 & 0.051 & $0.0011^{* * * *}$ & 0.280 & 0.010 & 0.3147 \\
\hline & Southeast & 0.459 & 0.548 & -0.089 & $0.0000^{* * * *}$ & 0.475 & -0.017 & 0.1445 \\
\hline \multirow{3}{*}{ Institution } & IPR & 0.089 & 0.091 & -0.002 & 0.8246 & 0.090 & -0.002 & 0.7998 \\
\hline & Private Univ & 0.228 & 0.265 & -0.038 & $0.0176^{* *}$ & 0.228 & -0.000 & 0.9685 \\
\hline & Public Univ & 0.684 & 0.644 & 0.040 & $0.0205^{* *}$ & 0.682 & 0.002 & 0.8484 \\
\hline
\end{tabular}

Source: authors' original work.

Table 5. Results of estimations

\begin{tabular}{|c|c|c|c|c|c|c|c|}
\hline & & \multicolumn{3}{|c|}{ Unmatched DID } & \multicolumn{3}{|c|}{ DID with PSM } \\
\hline & & Baseline & Follow-up & Effect & Baseline & Follow-up & Effect \\
\hline \multirow{3}{*}{ All collaborations } & Control & 16,669 & 44,428 & & 18,545 & 47,718 & \\
\hline & Treated & 18,848 & 53,853 & & 18,848 & 53,853 & \\
\hline & Difference & 2,179 & $9,425^{* * *}$ & $7,246^{* *}$ & 0,304 & $6,135^{* * *}$ & $5,832^{* * * *}$ \\
\hline \multirow{3}{*}{$\begin{array}{c}\text { Long-term } \\
\text { collaborations }\end{array}$} & Control & 16,669 & 44,428 & & 18,011 & 47,044 & \\
\hline & Treated & 18,080 & 54,142 & & 18,136 & 54,31 & \\
\hline & Difference & 1,411 & $9,714^{* * *}$ & $8,303^{*}$ & 0,125 & $7,266^{* * *}$ & $7,141^{* * * *}$ \\
\hline \multirow{3}{*}{$\begin{array}{c}\text { Other } \\
\text { collaborations }\end{array}$} & Control & 16,669 & 44,428 & & 18,49 & 47,447 & \\
\hline & Treated & 19,315 & 53,677 & & 19,352 & 53,773 & \\
\hline & Difference & 2,646 & $9,250^{* * * *}$ & $6,604^{*}$ & 0,862 & $6,325^{* * *}$ & $5,463^{* *}$ \\
\hline
\end{tabular}


Table 6. Robustness check - DiD Estimations with different PSM Specifications

\begin{tabular}{c|cccccc}
\multicolumn{1}{c}{$\mathrm{A}$} & $\mathrm{B}$ & $\mathrm{C}$ & $\mathrm{D}$ & $\mathrm{E}$ & $\mathrm{F}$ \\
\hline All Collaborations & $5.832^{* * *}$ & $5.999^{* * *}$ & $5.749^{* * *}$ & $5.703^{* * *}$ & $6.019^{* * *}$ & $5.983^{* * *}$ \\
\hline $\begin{array}{c}\text { LT - Long-term } \\
\text { collaborations }\end{array}$ & $7.141^{* * * *}$ & $7.402^{* * *}$ & $7.206^{* * *}$ & $7.279^{* * *}$ & $6.852^{* * *}$ & $7.073^{* * *}$ \\
\hline $\begin{array}{c}\text { ST - Short-term } \\
\text { collabotration }\end{array}$ & $5.463^{* *}$ & $5.640^{* *}$ & $5.337^{* *}$ & $5.219^{* * *}$ & $5.604^{* *}$ & $5.644^{* *}$ \\
\hline$\Delta=$ LT - ST & 1.678 & 1.762 & 1.869 & 2.06 & 1.248 & 1.429 \\
\hline
\end{tabular}

A - Original Specification (probit epanechnikov kernel 0.06 bandwith). The modified parameter from original PSM in the alternative specification were: B - logit. C -biweight. D - 0.04 bandwith. E - 0.08 bandwith. F - tricube.

Table 7. Effects of the long-term collaboration over time

Effect over time - Long-term collaborations

\begin{tabular}{lcccccc}
\hline Period & $\mathrm{A}$ & $\mathrm{B}$ & $\mathrm{C}$ & $\mathrm{D}$ & $\mathrm{E}$ & $\mathrm{F}$ \\
\hline $02-04$ & 1.536 & 1.457 & 1.554 & 1.583 & 1.522 & 1.528 \\
\hline $02-06$ & $5.038^{* * *}$ & $5.186^{* * *}$ & $5.106^{* * *}$ & $5.171^{* * *}$ & $4.820^{* *}$ & $4.945^{* * *}$ \\
\hline $02-08$ & $7.141^{* * *}$ & $7.402^{* * *}$ & $7.206^{* * *}$ & $7.279^{* * *}$ & $6.852^{* * *}$ & $7.073^{* * *}$
\end{tabular}

A - Original Specification (probit epanechnikov kernel 0.06 bandwith). The modified parameter from original PSM in the alternative specification were: B - logit. C -biweight. D - 0.04 bandwith. E - 0.08 bandwith. F - tricube. 